\title{
Article \\ Dissecting the Supramolecular Dispersion of Fullerenes by Proteins/Peptides: Amino Acid Ranking and Driving Forces for Binding to $\mathrm{C}_{60}$
}

\author{
Tainah Dorina Marforio *, Alessandro Calza, Edoardo Jun Mattioli (D), Francesco Zerbetto and Matteo Calvaresi *(D)
}

check for updates

Citation: Marforio, T.D.; Calza, A.; Mattioli, E.J.; Zerbetto, F.; Calvaresi, M. Dissecting the Supramolecular Dispersion of Fullerenes by Proteins/Peptides: Amino Acid Ranking and Driving Forces for Binding to $\mathrm{C}_{60}$. Int. J. Mol. Sci. 2021, 22, 11567. https://doi.org/10.3390/ ijms222111567

Academic Editors: Valentina Villari and Paula Ferreira

Received: 10 October 2021

Accepted: 22 October 2021

Published: 26 October 2021

Publisher's Note: MDPI stays neutral with regard to jurisdictional claims in published maps and institutional affiliations.

Copyright: (C) 2021 by the authors. Licensee MDPI, Basel, Switzerland. This article is an open access article distributed under the terms and conditions of the Creative Commons Attribution (CC BY) license (https:/ / creativecommons.org/licenses/by/ $4.0 /)$.
Dipartimento di Chimica "Giacomo Ciamician", Alma Mater Studiorum-Università di Bologna, 40126 Bologna, Italy; alessandro.calza2@studio.unibo.it (A.C.); edoardojun.mattioli2@unibo.it (E.J.M.); francesco.zerbetto@unibo.it (F.Z.)

* Correspondence: tainah.marforio2@unibo.it (T.D.M.); matteo.calvaresi3@unibo.it (M.C.)

Abstract: Molecular dynamics simulations were used to quantitatively investigate the interactions between the twenty proteinogenic amino acids and $\mathrm{C}_{60}$. The conserved amino acid backbone gave a constant energetic interaction $\sim 5.4 \mathrm{kcal} \mathrm{mol}^{-1}$, while the contribution to the binding due to the amino acid side chains was found to be up to $\sim 5 \mathrm{kcal} \mathrm{mol}^{-1}$ for tryptophan but lower, to a point where it was slightly destabilizing, for glutamic acid. The effects of the interplay between van der Waals, hydrophobic, and polar solvation interactions on the various aspects of the binding of the amino acids, which were grouped as aromatic, charged, polar and hydrophobic, are discussed. Although $\pi-\pi$ interactions were dominant, surfactant-like and hydrophobic effects were also observed. In the molecular dynamics simulations, the interacting residues displayed a tendency to visit configurations (i.e., regions of the Ramachandran plot) that were absent when $\mathrm{C}_{60}$ was not present. The amino acid backbone assumed a "tepee-like" geometrical structure to maximize interactions with the fullerene cage. Well-defined conformations of the most interactive amino acids (Trp, Arg, Met) side chains were identified upon $\mathrm{C}_{60}$ binding.

Keywords: fullerene; amino acids; proteins; peptides; molecular dynamics simulations; nanobiotechnology; nanobio interface; MM/GBSA; $\pi-\pi$ stacking

\section{Introduction}

In biomedical applications, fullerenes have wide potential [1-3] due to their (i) antioxidant and radical scavenging capacity; (ii) neuroprotective action; iii) biological activity as antiviral, antibacterial, antiapoptotic molecules; (iv) enzyme inhibition activity; (v) photosensitizing ability in photodynamic anticancer and antimicrobic therapy; (vi) capacity as contrast agents; and (vii) drug and gene delivery ability. The extreme hydrophobic nature of fullerenes [4] has, however, prevented their biological application, making them of scarce bioavailability in physiological environments. Different strategies have been explored to promote fullerenes' dispersion in water. Initial studies of the biological activity of fullerenes involved the functionalization of the hydrophobic cage with hydrophilic moieties to enhance their water solubility [5,6]. For instance, carboxy- and malonyl-derivatives of $\mathrm{C}_{60}$ were demonstrated to be an interesting class of reactive oxygen species( ROS) scavenging agents [7-10]. However, the most appealing fullerene derivatives for biological applications are fullerene-biomolecule conjugates [11], such as fulleroamino acids and fulleropeptides [12-15], in which the functionalization moiety is both hydrophilic and biocompatible. Fulleroamino acids and fulleropeptides are at least partially water soluble, and demonstrated high biological and pharmacological activities [12-15]. Fullerenes were also chemically conjugated to proteins [15-17] such as azurin [16], thyroglobulin [17], and albumins [17] to improve their functionality (electronic communication or targeting) and biocompatibility. 
The direct derivatization of a fullerene with amino acids or its chemical conjugation with peptides and proteins makes a fullerene biocompatible and improves its water solubility, but, as with any fullerene functionalization procedure, these processes degrade the peculiar chemical-physical properties of $C_{60}$ [18]. Supramolecular approaches can preserve these properties [19]. Recently, it was demonstrated that it is possible to use peptides [20] and proteins [21-29] as supramolecular hosts for the non-covalent dispersion of fullerenes [21]. Different proteins, such as albumins [22,23], lysozyme [23-26], pepsin [27], trypsin [27], or natural protein surfactants [28] were used for the mono-molecular dispersion of pristine fullerenes in a physiological environment.

Pioneering approaches based on reverse docking were attempted to identify proteins characterized by one or more hydrophobic pockets suitable for accommodating a fullerene [30-32]. Proteins were also engineered into scaffolds for $\mathrm{C}_{60}$ binding on the protein surface $[33,34]$.

However, a full comprehension of the process governing the association of peptides/proteins with fullerenes is still lacking. Detailed knowledge about the formation of complexes of peptides/proteins with $\mathrm{C}_{60}$ can advance bio-based applications of fullerenes [35]. For instance, inhibitors can be developed by increasing the peptide/fullerene binding [32,36-38], the antioxidant properties of fullerenes can be enhanced by protein interaction [39], and fullerenes' ability to generate ROS under irradiation can be tuned $[20,23,25,26,40]$.

Amino acids are the elementary building blocks of proteins and, therefore, they must be the starting point for investigating the complex phenomena that govern the interactions between peptides/proteins and fullerenes [41,42].

In this study, we determined the adsorption energies of all twenty natural amino acids with $\mathrm{C}_{60}$, ranked their propensity to interact with $\mathrm{C}_{60}$, and identified the thermodynamic contributions responsible for their interactions. The atomistic details of the interaction between amino acids and fullerene were obtained using molecular dynamics (MD) simulations. MD simulations are a powerful tool to unravel the mechanisms of interaction of proteins with carbon nanomaterials, providing detailed structural information [43]. An analysis of the binding components of the energy was performed by using Molecular Mechanics/Generalized Born Surface Area (MM/GBSA) and Molecular Mechanics/Poisson-Boltzmann Surface Area (MM/PBSA) methodologies [44]. The analysis of the energy contributions to the binding between amino acids and $\mathrm{C}_{60}$ can offer guidelines of general applicability to understand and design protein-fullerene interactions. This information is crucial to (i) understand in detail the driving forces in the interaction between peptides/proteins and fullerenes, (ii) enhance our ability to engineer such complexes, (iii) predict a priori the strength of adsorption and structure of a protein upon fullerene binding.

\section{Results and Discussion}

The geometries of the twenty $\mathrm{C}_{60}$-amino acid complexes were built. The amino acids were capped by acetyl (ACE) and n-methyl amide (NME) groups at the $\mathrm{N}$ - and $\mathrm{C}$-termini (ACE-AA-NME), (Scheme 1) to reproduce the typical interactions between $\mathrm{C}_{60}$ and an amino acid inserted into the peptide/protein sequence.

Subsequently, $100 \mathrm{~ns}$ of molecular dynamics simulations were carried out for each complex to sample the possible interaction geometries between the $\mathrm{C}_{60}$ and the twenty amino acids. Post-processing of the trajectories allowed us to estimate the binding energy between the amino acids and the $\mathrm{C}_{60}$ and the binding components of the energy by $\mathrm{MM} / \mathrm{GBSA}$ and MM/PBSA. 
<smiles>[R7][C@H](SC)C(=O)N[C@H]([R])C(=O)N[C@@H]([PH])SC</smiles>

c)<smiles>[R][C@H](NC(C)=O)C(=O)NC</smiles>

b)<smiles>[2H][C@@H]([NH3+])C(=O)[O-]</smiles>

d)

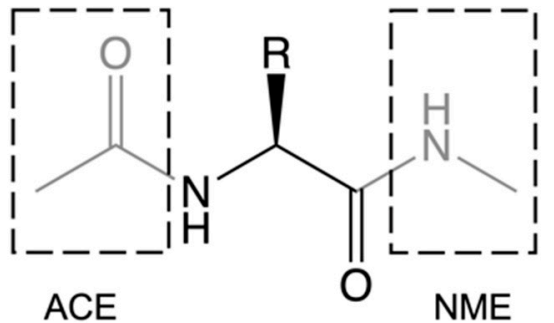

Scheme 1. (a) Amino acid (in black) inserted in a peptide/protein sequence. (b) Amino acid in zwitterionic form. (c,d) Amino acid capped with ACE/NME.

\subsection{Ranking the Binding Energies}

The interaction energies between the capped amino acids and the $\mathrm{C}_{60}$ were calculated at MM/GBSA and MM/PBSA levels of theory (Figure S1). The results of the two methodologies were very similar (MM/GBSA systematically provided a more stabilizing interaction energy of $-0.5 \mathrm{kcal} \mathrm{mol}^{-1}$ compared to MM/PBSA, due to the different treatment of solvation). In the following, we describe in detail the MM/GBSA ranking, because such calculations are faster (a crucial issue for applications in virtual screening or MD simulations of large biosystems) and mostly because the GB terms are pair-wise decomposable (PB non-polar solvation energies are currently not decomposable) [44].

The ranking obtained by the binding energies of the capped amino acids (Figure 1a) and of the amino acid side chains (Figure 1b) was the same. This implied a constant contribution from the conserved amino acid backbone (with a value of $E_{\text {binding }} \sim 5.4 \mathrm{kcal} \mathrm{mol}^{-1}$, similar to the interaction of Gly with $\mathrm{C}_{60}$ ). The contribution due to the amino acid side chains varied and was responsible for the different interactions of the twenty amino acids (from $E_{\text {binding }}=-5.0 \mathrm{kcal} \mathrm{mol}^{-1}$ of Trp to $E_{\text {binding }}=+0.1 \mathrm{kcal} \mathrm{mol}^{-1}$ of Glu).

a)<smiles>[R]C(NC(C)(F)F)C(=O)NC</smiles>

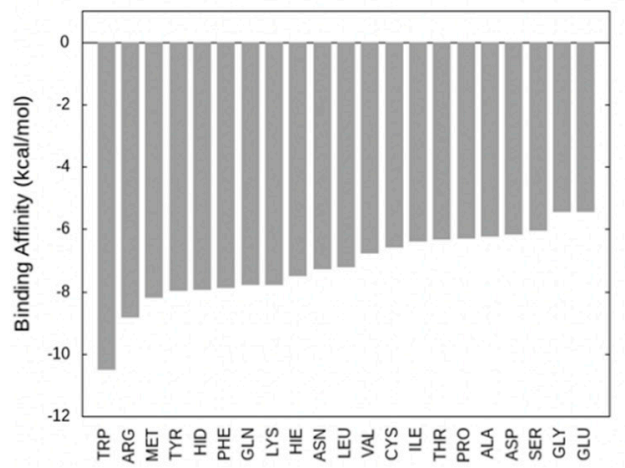

b)
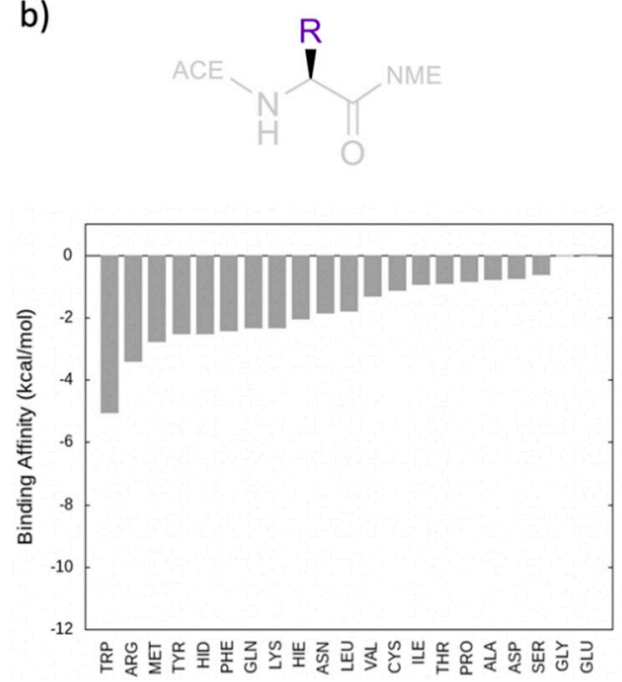

Figure 1. Binding energy between the (a) whole capped amino acid and (b) amino acid side chain and $\mathrm{C}_{60}$ calculated by MM/GBSA for the twenty proteinogenic amino acids. 
Van der Waals interactions are the driving force in binding (Figure 2) [35,45]. It is important to emphasize that in the present model, the van der Waals term includes $\pi-\pi$ interactions.

TOTAL

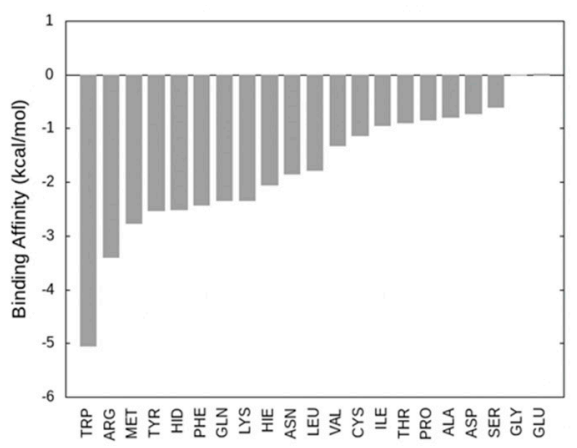

$E_{\mathrm{GB}}$

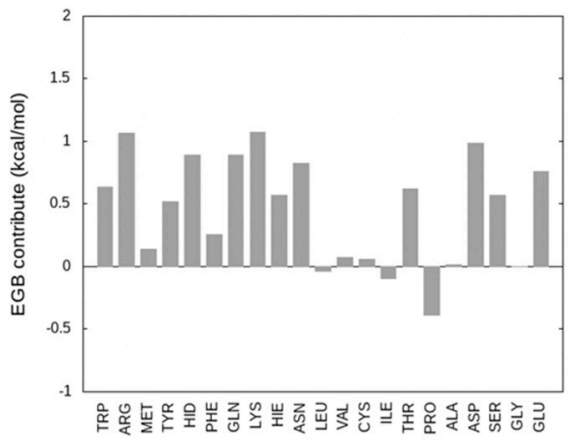

VDW

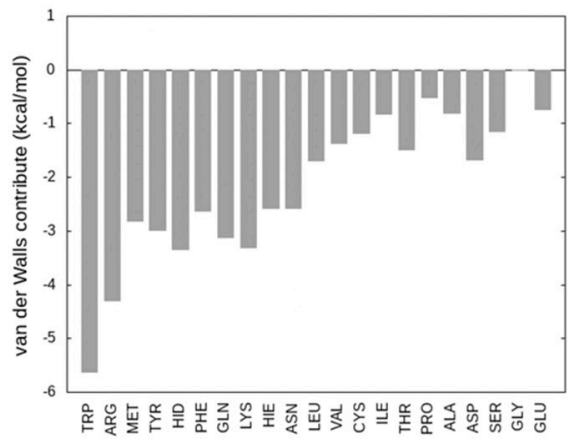

$\mathbf{E}_{\text {SURF }}$

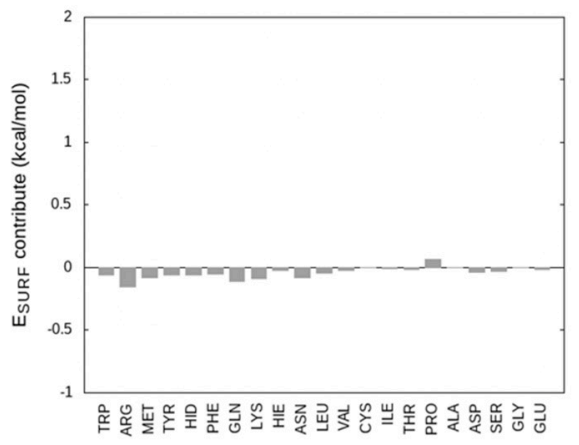

Figure 2. Analysis of the components of the binding energy of the amino acid side chains by MM/GBSA.

Hydrophobic interactions, i.e., nonpolar solvation ( $\left.E_{S U R F}\right)$, assist binding, even if the corresponding values are small. Contributions to the nonpolar solvation originate in the hydrophobic parts of some amino acids, such as aliphatic chains or aromatic rings, which, upon the formation of the complex with $\mathrm{C}_{60}$, come into contact with the hydrophobic surface of the $\mathrm{C}_{60}$ cage instead of water molecules, which interact unfavorably with these regions.

Polar solvation terms $\left(\mathrm{E}_{\mathrm{GB}}\right)$ are quite important and deserve an accurate analysis. These terms are detrimental to binding and their contribution generally features an energy level greater than zero, i.e., it is destabilizing. The hydrophilic part of many amino acids, upon interaction with $\mathrm{C}_{60}$, is forcedly desolvated, increasing the energy of the system. This is particularly evident in the cases of charged (Arg, Lys, Glu, Asp) and polar (Gln, Asn, Thr, Ser) amino acids: these residues, after interaction with $\mathrm{C}_{60}$, are screened from water and are no longer able to maintain a full solvation shell. Other amino acids commonly considered hydrophobic, such as Trp, Tyr, and His, are also characterized by positive desolvation energy, albeit to a lesser extent. This behavior is due to the presence of hydrophilic moieties, such as the $\mathrm{N}-\mathrm{H}$ or $\mathrm{O}-\mathrm{H}$ groups, which are desolvated upon $\mathrm{C}_{60}$ binding. Of course, purely hydrophobic residues, such as Met, Leu, Val, Ile, Pro, Ala and Gly, do not suffer this energy penalty upon binding.

\subsubsection{Aromatic Amino Acids}

If we consider the extended $\pi$-system of the fullerene, it is not surprising that aromatic amino acids such as tryptophan, tyrosine, phenylalanine, and histidine interacted the most with it (Figure 3) [20,24,33-35,39,46-54]. In particular, Trp exhibited the largest value of binding energy among the twenty proteinogenic amino acids. Trp is commonly 
recognized as the amino acid that most interacts with carbon nanoparticles, such as carbon nanotubes [55] or graphene [56]. The large indole group of tryptophan also demonstrated the largest interaction with the $C_{60}\left(E_{\text {binding }}=-5.0 \mathrm{kcal} \mathrm{mol}^{-1}\right)$, followed by tyrosine $\left(E_{\text {binding }}=-2.5 \mathrm{kcal} \mathrm{mol}^{-1}\right)$, histidine $\left(E_{\text {binding }}=-2.5 \mathrm{kcal} \mathrm{mol}^{-1}\right)$, and phenylalanine $\left(E_{\text {binding }}=-2.4 \mathrm{kcal} \mathrm{mol}^{-1}\right)$.

a)

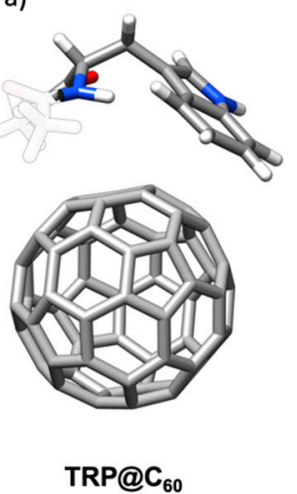

b)

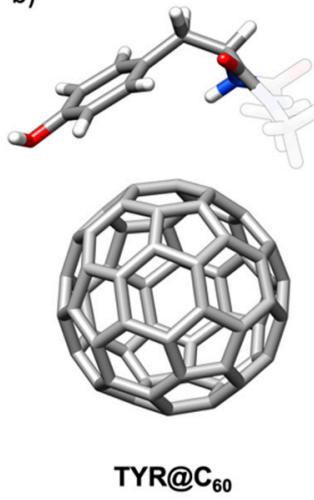

c)
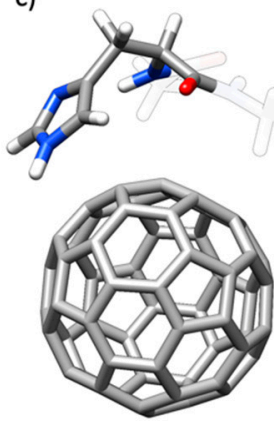

HIS@ $C_{60}$ d)
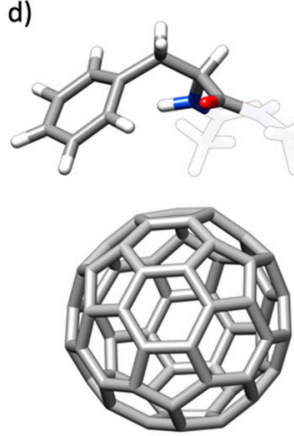

PHE@C 60

Figure 3. Snapshots from the MD of the interactions of aromatic amino acids (a) Trp, (b) Tyr, (c) His and (d) Phe with $\mathrm{C}_{60}$. For each amino acid, the most interactive configuration is shown.

Experimentally, in $\mathrm{C}_{60} @$ lysozyme, $\pi$-stacking interactions between $\mathrm{C}_{60}$ and Trp (sandwichlike for Trp62 and T-shape-like for Trp63) are crucial for binding [24,35,51]. Analogously, in a peptide designed to recognize $C_{60}, C_{60}$ is wedged between two Tyr residues [33]. Moreover, consensus tetratricopeptide repeat proteins (CTPR) were identified as good candidates for hosting fullerenes due to the high abundance of tyrosine (six residues per repeat unit) [34]. Finally, phenylalanines were used as recognizing moieties in peptidic nanotweezers [20].

\subsubsection{Charged Amino Acids}

Besides $\pi-\pi$ interactions, electron rich fullerenes can also interact with amino acids through (i) cation- $\pi$ [54], and (ii) non-standard hydrogen bonds, in which $\mathrm{C}_{60}$ acts as a hydrogen bond acceptor [47]. For this reason, positively charged amino acids, such as arginine $\left(E_{\text {binding }}=-3.4 \mathrm{kcal} \mathrm{mol}^{-1}\right)$ or lysine $\left(E_{\text {binding }}=-2.3 \mathrm{kcal} \mathrm{mol}^{-1}\right)$, interacted strongly with the $\mathrm{C}_{60}$, while negatively charged amino acids, such as aspartate $\left(E_{\text {binding }}=-0.7 \mathrm{kcal} \mathrm{mol}^{-1}\right)$ and glutamate $\left(E_{\text {binding }}=+0.1 \mathrm{kcal} \mathrm{mol}^{-1}\right)$ were among the least interacting residues (Figure 4).

a)

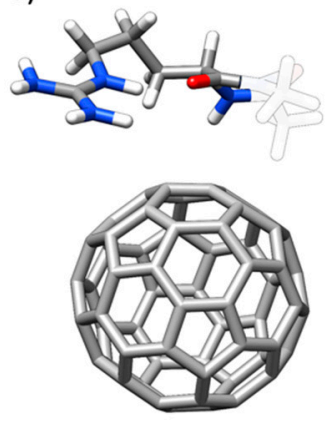

$A R G @ C_{60}$ b)
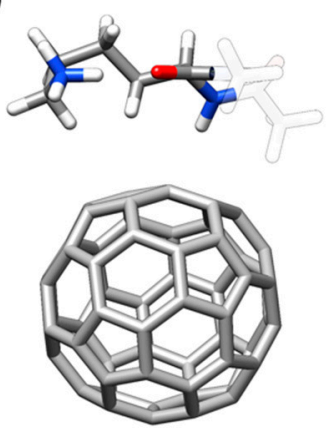

LYS@C 60 c)
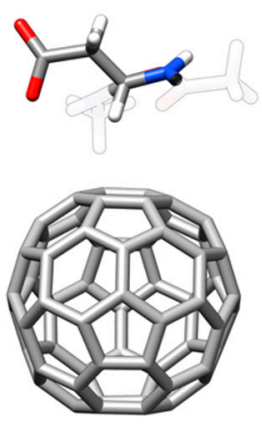

$\mathrm{ASP}_{60}$ d)
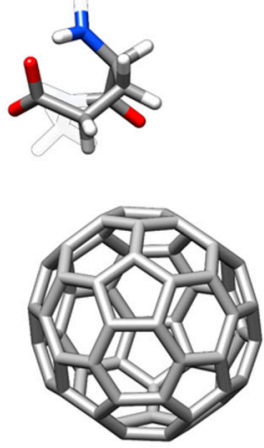

GLU@C 60

Figure 4. Snapshots from the MD of the interactions of charged amino acids (a) Arg, (b) Lys, (c) Asp and (d) Glu with $\mathrm{C}_{60}$. For each amino acid, the most interactive configuration is shown. 
After Trp, Arg was the second amino acid that most strongly interacted with the $\mathrm{C}_{60}$. The high affinity of Arg with carbon nanomaterials is well-known experimentally $[57,58]$ and widely discussed computationally [57,59-61]. The affinity of Lys with $C_{60}$ is lower than that of Arg, although both are positively charged and their side chains are characterized by the same surface (the accessible surface area, ASA, is $2.8 \mathrm{~nm}^{2}$ for Lys and $2.9 \mathrm{~nm}^{2}$ for Arg). The presence of the guanidinium group plays a crucial role in the preferential adsorption of Arg onto carbon nanomaterials because of the presence of: (i) the $\pi-\pi$ interactions that the planar guanidinium group establishes with $\mathrm{C}_{60}$ (the $\mathrm{vdW}$ interactions of the Arg side chain are $4.3 \mathrm{kcal} \mathrm{mol}^{-1}$, while for Lys they are $3.3 \mathrm{kcal} \mathrm{mol}^{-1}$ ); (ii) the surfactant-like behavior of Arg when interacting with hydrophobic nanoparticles. The Arg residues orient themselves so that the guanidinium head anchors on the cage of the fullerene, while the aliphatic chain sticks to its hydrophobic surface. In this way, Arg effectively becomes a surfactant that creates an amphiphilic shield around the hydrophobic nanoparticle [61].

\subsubsection{Polar Amino Acids}

Polar amino acids, such as glutamine, asparagine, cysteine, threonine, and serine, are amphiphilic residues that interact with $\mathrm{C}_{60}$, producing surfactant-like interactions (Figure 5).

a)
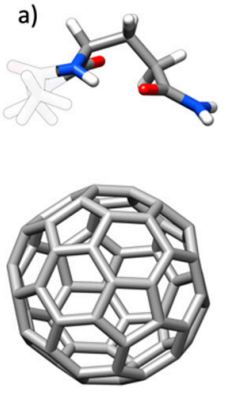

GLN@C 60 b)
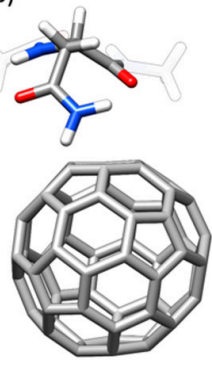

ASN@C 60 c)
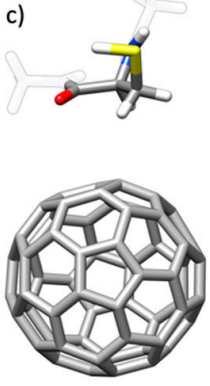

CYS@C d)


THR@ $\mathrm{C}_{60}$ e)
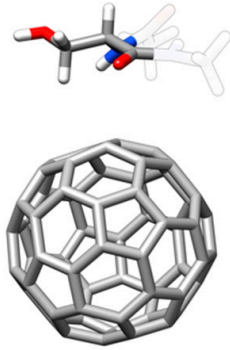

SER@C 60

Figure 5. Snapshots from the MD of the interactions of polar amino acids (a) Gln, (b) Asn, (c) Cys, (d) Thr and (e) Ser with $\mathrm{C}_{60}$. For each amino acid, the most interactive configuration is shown.

In this case, the hydrophobic part of the residues interacted with the fullerene surface, while the hydrophilic part continued to interact with water. The affinity of the residues is directly proportional to the vdW interactions that the hydrophobic chain established with the $C_{60}$ cage. For example, $G \ln \left(E_{\text {binding }}=-3.1 \mathrm{kcal} \mathrm{mol}^{-1}\right)$ interacted more strongly than Asn $\left(E_{\text {binding }}=-2.6 \mathrm{kcal} \mathrm{mol}^{-1}\right)$ due to a longer aliphatic chain, and Thr $\left(E_{\text {binding }}=-1.5 \mathrm{kcal} \mathrm{mol}^{-1}\right)$ interacted more strongly than Ser $\left(E_{\text {binding }}=-1.1 \mathrm{kcal} \mathrm{mol}^{-1}\right)$ due to the presence of an additional methyl group. The affinity of the residues was also inversely proportional to the desolvation energy penalty. Cys interacted more strongly than Ser because the desolvation of the more polar -OH group $\left(0.6 \mathrm{kcal} \mathrm{mol}^{-1}\right)$ represented a higher energy penalty than the desolvation of the less polar -SH group $\left(0.1 \mathrm{kcal} \mathrm{mol}^{-1}\right)$.

\subsubsection{Hydrophobic Amino Acids}

In protein/peptide-fullerene complexes, several aliphatic residues are usually part of the $\mathrm{C}_{60}$ binding pocket and contribute to binding [33,35,49]. Hydrophobic interactions can be established with methionine, valine, isoleucine, leucine, proline, alanine, and glycine (Figure 6). The hydrophobic effect can be defined as the absence of a desolvation penalty in the binding of a residue with the $\mathrm{C}_{60}$; indeed, even negative values in the $\mathrm{E}_{\mathrm{GB}}$ are found. Concurrently, the larger the contact area between the amino acid side chain and the $\mathrm{C}_{60}$, the larger the stabilizing effect due to vdW interactions (dispersion forces). Shape complementarity represents a quick way to estimate both the stabilizing van der Waals and hydrophobic interactions between proteins and carbon nanomaterials $[21,45,62,63]$. 
a)

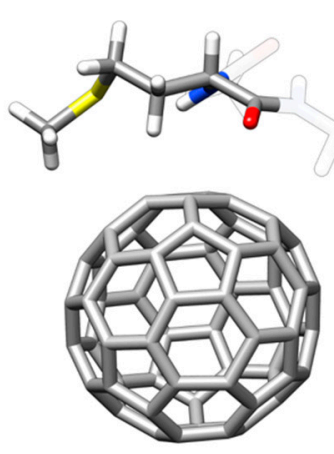

MET@C 60 b)
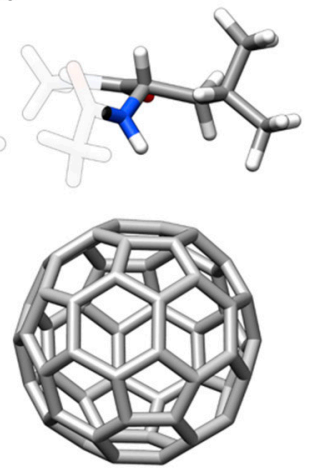

VAL@C 60 c)
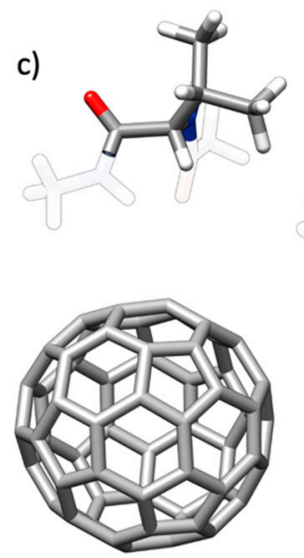

ILE@C 6 d)
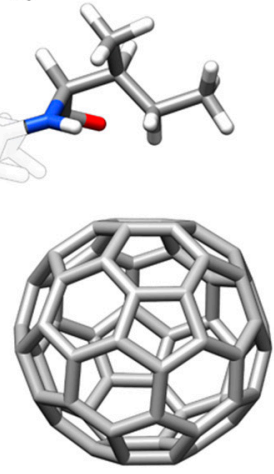

LEU@ $\mathrm{C}_{60}$ e)
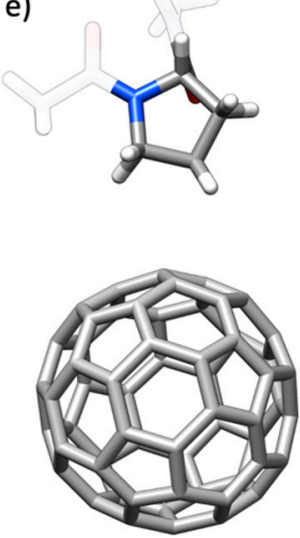

PRO@C 60 f)
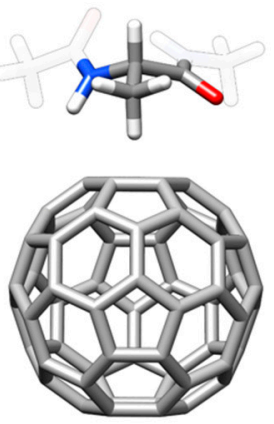

ALA@C 60 g)
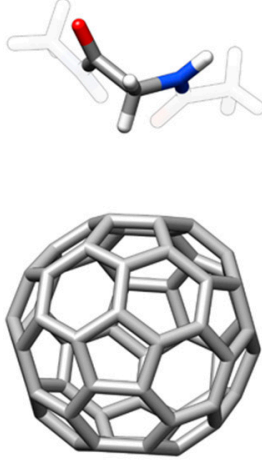

GLY@C 60

Figure 6. Snapshots from the MD of the interactions of hydrophobic amino acids (a) Met, (b) Val, (c) Ile, (d) Leu, (e) Pro, (f) Ala and (g) Gly with $\mathrm{C}_{60}$. For each amino acid, the most interactive configuration is shown.

In this context, the behavior of Met deserves special attention. Met was the amino acid with the third strongest level of interaction in the ranking in this study. The presence of a sulfur atom strongly favors the interaction of the side chain with the $\mathrm{C}_{60}$. This stabilizing interaction can be interpreted as the soft sulfur atom that strongly interacts with the soft and electron-rich fullerene cage. In practice, a deep potential energy well is formed by the interaction of the $S$ atom of methionine with the $C$ atoms of the $C_{60}$. Such strong stabilization is not present for pure aliphatic chains such as Val, Ile, Leu.

\subsection{Conformations of Amino Acids in Water and Upon Interaction with $C_{60}$}

To investigate the effect of the absorption of amino acids on $\mathrm{C}_{60}$, for the three most interactive residues (Trp, Arg, and Met) we carried out a thorough conformational analysis of the amino acids in water and upon $\mathrm{C}_{60}$ binding.

\subsubsection{Analysis of the Torsional Angles of the Amino Acid Backbone}

We sampled the torsional angles phi $(\varphi)$ and psi $(\psi)$ of the amino acid backbone during the MD simulations in water and upon interaction with $\mathrm{C}_{60}$. The simulations of the amino acids in water showed that the "classic" and more stable regions of the right-handed $\alpha$-helix and $\beta$-sheet were the most populated (Figure 7a-c). By contrast, the binding with $\mathrm{C}_{60}$ altered the $\varphi-\psi$ distributions by affecting the conformations observed in water and the amino acids sampled a new $\varphi-\psi$ region (indicated by a red circle in Figure $7 d-f$ ), which 
was rarely observed in bulk water. The amino acids in this region of the Ramachandran plot assumed a "tepee-like" geometrical structure to optimize the interactions with the $\mathrm{C}_{60}$ cage of the side chain of the amino acid and the $\mathrm{N}$-terminal and C-terminal peptide bonds, as represented in Figure 7g-i.

a)



d)

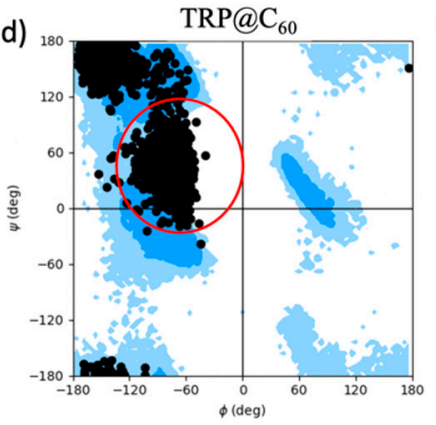

g)

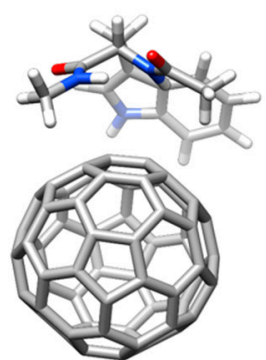

b)

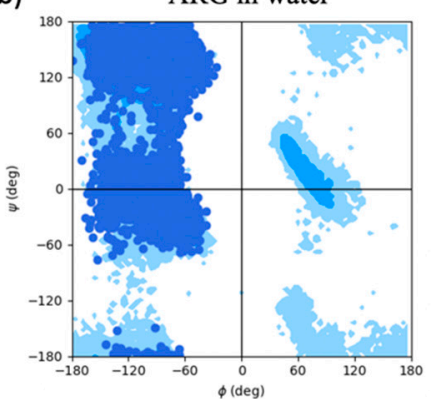

e)

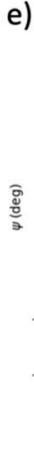

h)

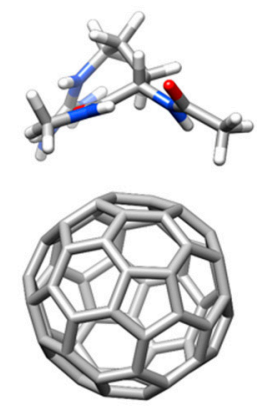

c)

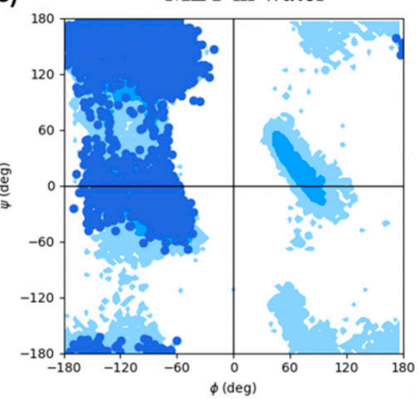

f)

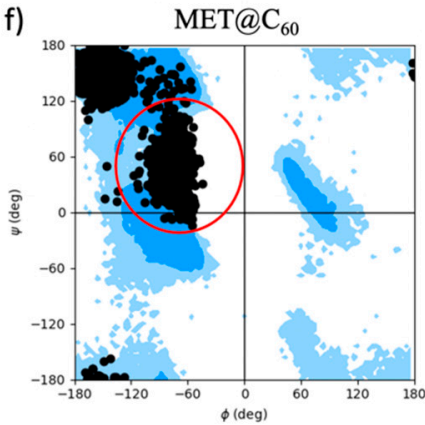

i)

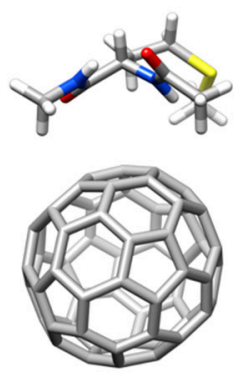

Figure 7. The distribution of the backbone torsional angles (a-f) obtained for Trp, Arg, and Met in (a-c) bulk water and (d-f) upon $\mathrm{C}_{60}$ binding. The background regions (shown in cyan) represent the sterically allowed Ramachandran angles. Blue $(\mathbf{a}-\mathbf{c})$ and black $(\mathbf{d}-\mathbf{f})$ points represent the torsional angles phi $(\varphi)$ and psi $(\psi)$ of the amino acids observed during the MD simulations. (g-i) Representative structures of the "tepee-like" conformations of Trp@ $\mathrm{C}_{60}(\mathrm{~g}), \operatorname{Arg} @ \mathrm{C}_{60}(\mathbf{h})$, and $\mathrm{Met}_{60}(\mathbf{i})$.

\subsubsection{Analysis of the Side Chain Conformation of the Amino Acids upon $\mathrm{C}_{60}$ Binding}

Orientational preferences of the side chains of the amino acids upon $\mathrm{C}_{60}$ binding clearly appeared in the Free Energy Surfaces, FES, of the complexes of Trp and Arg (Figure 8 and Figure S2).

The FES of Trp@ $\mathrm{C}_{60}$ displayed the existence of two minima. In the more populated/stable minimum, the conformation was sandwich-like. It was characterized by $\pi-\pi$ interactions between the indole ring of Trp and the fullerene cage (conformation I in Figure 8a). In the less populated minimum, the conformation was T-shape-like; the indole group assumed a perpendicular configuration with respect to the fullerene cage (conformation II in Figure 8a). These conformations were experimentally observed and discussed in the $\mathrm{C}_{60} @$ lysozyme complex, in which sandwich-like interactions were recognized for Trp62 and T-shape-like interactions for Trp63. 
a)

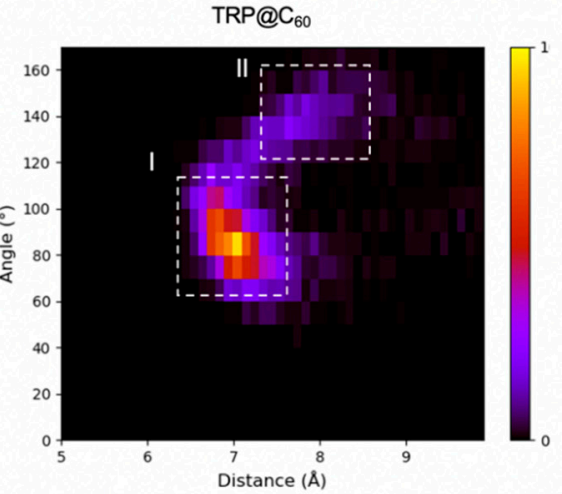

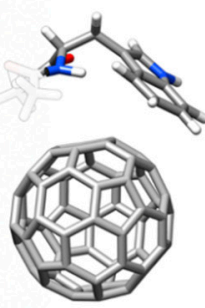

I
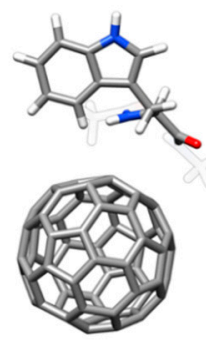

II

b)

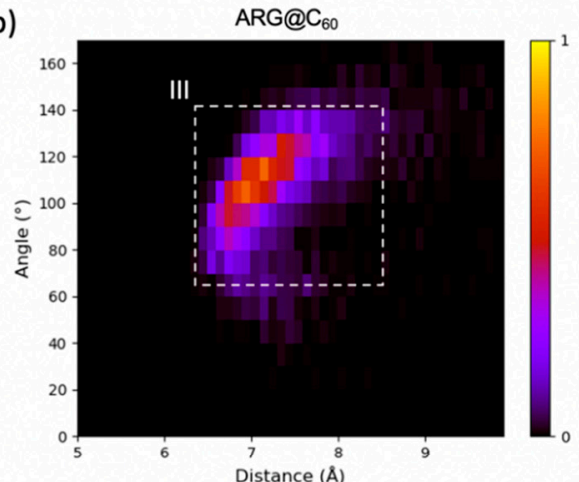

MET@C 60

c)

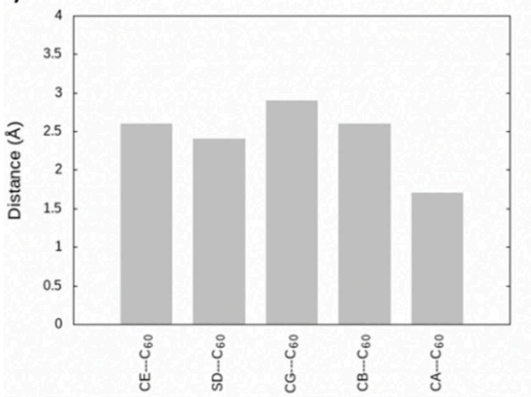

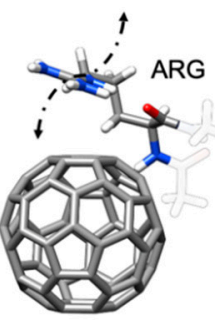

III
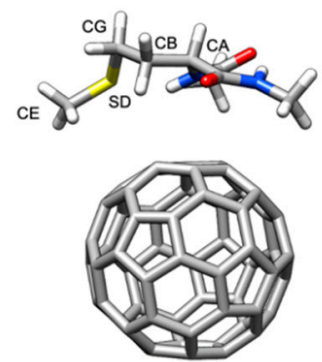

Figure 8. (a,b) Normalized free energy surfaces of (a) $\operatorname{Trp} @ \mathrm{C}_{60}$ and (b) $\operatorname{Arg} @ \mathrm{C}_{60}$. In (a) the $\mathrm{x}$ axis represents the distance between the center of mass $(\mathrm{COM})$ of the indole and the COM of the $\mathrm{C}_{60}$. The $y$ axis represents the angle between the (i) $\mathrm{COM}\left(\mathrm{C}_{60}\right)-\mathrm{COM}$ (indole) and (ii) indole $\mathrm{N}-\mathrm{H}$ vectors. In (b) the $x$ axis represents the distance between the center of mass (COM) of the guanidinium group and the COM of the $\mathrm{C}_{60}$. The $y$ axis represents the angle between the (i) $\mathrm{COM}\left(\mathrm{C}_{60}\right)-\mathrm{COM}$ (guanidinium) and (ii) guanidinium $\mathrm{CZ}-\mathrm{NH} 1$ vectors. (c) Mean distance during the MD simulation between $\mathrm{COM}\left(\mathrm{C}_{60}\right)$ and $\mathrm{CA}, \mathrm{CB}, \mathrm{CG}, \mathrm{SD}$, and $\mathrm{CE}$ atoms in Met.

The FES of Arg@ $\mathrm{C}_{60}$ displayed a single minimum, corresponding to the establishment of $\pi-\pi$ interactions between the planar guanidinium group and the $\mathrm{C}_{60}$. This minimum was broader if compared with that of the Trp complex because the smaller guanidinium group adhered less to $\mathrm{C}_{60}$, if compared to the indole group, and may have rotated freely towards the $\mathrm{C}_{60}$ surface.

In the case of Met@ $\mathrm{C}_{60}$ we analyzed the gluing of the Met side chain to the $\mathrm{C}_{60}$ cage. The CA atom was anchored to $\mathrm{C}_{60}$ by the interactions of the amino acid also with its backbone, and the mean distance during the MD simulation was small (1.7 $\AA$ ). However, all the other atoms of the aliphatic side chain remained attached to the surface of the $\mathrm{C}_{60}$ during the MD simulation in a "hug" to the fullerene cage. The mean distances of all the atoms of the Met side chain remain close to the $\mathrm{C}_{60}$ 's surface, (ranging from 2.4 to $2.9 \AA$ ) and, unsurprisingly, the sulfur atom acted as the ligand. In fact, even if it was characterized 
by a larger vdW radius compared to $C$ atoms, the $S$ atom was, on average, the closest to the $\mathrm{C}_{60}$ after $\mathrm{CA}(2.4 \AA)$.

\section{Materials and Methods}

\subsection{System Setup}

Amber force fields ff14SB [64] was used to model the amino acids (AA). The twenty proteinogenic amino acids (Ala, Arg, Asn, Asp, Cys, Glu, Gln, Gly, Hie, Ile, Leu, Lys, Met, Phe, Pro, Ser, Thr, Trp, Tyr, and Val) were considered in their physiological protonation state. For the histidine, both the protomers HID (Nס1-protonated histidine) and HIE (Nع1protonated histidine) were taken in account. The amino acids were capped by acetyl (ACE) and n-methyl amide (NMA) groups at the $\mathrm{N}$ - and C-termini (ACE-AA-NME), to reproduce the typical interactions between $\mathrm{C}_{60}$ and a peptide/protein host. The $\mathrm{C}_{60}$ carbon atoms were modelled as uncharged Lennard-Jones particles by using sp2 carbon parameters taken from the ff14SB force field [64].

\section{2. $M D$ Simulations}

AMBER 16 was used to run the simulations [65]. A total of 1000 steps of steepest descent minimization were performed with SANDER on the generated ACE-AA-NME@ $\mathrm{C}_{60}$ complexes. The minimized structures (which were only cleared from severe steric clashes) were considered for a $1 \mathrm{~ns}$ equilibration step, and heated from 0 to $300 \mathrm{~K}$ (Langevin thermostat). Periodic boundary conditions (PBC) and Particle Mesh Ewald summation were used throughout (with a cut-off radius of $10 \AA$ for the direct space sum). The MD simulations of the amino acids were performed with explicit solvent by using the TIP3P water model. Chloride or sodium counterions were included to exactly neutralize the charged amino acids. At the end of the equilibration process, a production MD of $100 \mathrm{~ns}$ was carried out for every system at $300 \mathrm{~K}$.

\subsection{Molecular Mechanics/Generalized Born Surface Area (MM/GBSA) and Molecular Mechanics/Poisson-Boltzmann Surface Area (MM/PBSA) Analysis}

A total of 4000 snapshots were used for the MM/GB(PB)SA analysis [44]. An infinite cut-off was used for all the interactions. The electrostatic contribution to the solvation free energy was calculated with the Poisson-Boltzmann (PB) model or the Generalized Born (GB) model, as implemented in MMPBSA.py [66]. The nonpolar contribution to the solvation free energy was determined with solvent-accessible surface-area dependent terms.

\subsection{Conformational Analysis of the Amino Acids}

The Ramachandran plots and FES were obtained using MDAnalysis software [63,64]. The analysis of distances and angles in the MD trajectories was carried out by CPPTRAJ [67], as implemented in AMBER 16. The energy landscape of the amino acids interacting with $\mathrm{C}_{60}$ was visualized in terms of free-energy, which was projected as contour lines onto a two-dimensional space formed by two internal coordinates of the system. The free-energy change associated to the passage between two different states was $\Delta \mathrm{G}=-\mathrm{RT}\left(\ln \mathrm{p}_{1} / \mathrm{p}_{2}\right)$, where $\mathrm{R}$ is the ideal gas constant, $\mathrm{T}$ is the temperature, and $\mathrm{p}_{\mathrm{i}}$ is the probability of finding the system in state $i$. The two-dimensional space defined by the selected coordinates was divided into a grid and the free energy calculated for each bin of the grid. The $p_{i}$ values correspond to the number of times the molecular dynamics trajectory "visits" a given bin. The whole set of $G$ values was normalized $[68,69]$ in such a way that the lowest value (i.e., the most populated bin) corresponds to 1 .

\section{Conclusions}

The potential of fullerenes in bio-medical applications is significant and can only partly be exploited because their extremely hydrophobic nature makes them rare in physiological environments. Of all the strategies that have been developed to make fullerenes bio-available, the "Trojan horse" approach, in which they are stashed away in water-soluble 
proteins, appears to be the greenest and most environmentally friendly [21]. Propensity rules able to identify where a fullerene can be accommodated in a protein were developed. Molecular dynamics simulations that properly include van der Waals (including $\pi$-stacking), hydrophobic, and solvation interactions, were used to determine quantitatively the binding affinity of all the proteinogenic amino acids with $\mathrm{C}_{60}$. Van der Waals interactions are the driving forces in binding. Hydrophobic interactions, such as nonpolar solvation, assist in binding, even if the corresponding values are small. Polar solvation terms are detrimental to binding in the cases of charged and polar amino acids. Only purely hydrophobic residues do not suffer this energy penalty upon binding. The complex interplay between these terms makes tryptophan, arginine, and methionine the residues with the strongest interactions. A thorough conformational analysis of these amino acids demonstrated that upon $\mathrm{C}_{60}$ binding, the interacting residues show a tendency to visit configurations not "experienced" in water, and the backbone assumes a "tepee-like structure" to maximize the interaction with the $\mathrm{C}_{60}$ cage. The binding of $\operatorname{Trp}$ is characterized by $\pi-\pi$ interactions between the indole ring of Trp and the fullerene cage. These interactions may be sandwich-like (the most common) or T-shaped. Interactions of the $\pi-\pi$ type also govern the binding between $\mathrm{Arg}$ and $\mathrm{C}_{60}$ involving the planar guanidinium group and $\mathrm{C}_{60}$. The hydrophobic Met interacts with $\mathrm{C}_{60}$ in a "hug" between its aliphatic side chain and the fullerene cage. The presence of a sulfur atom strongly favors the interaction of the aliphatic side chain with $\mathrm{C}_{60}$.

Supplementary Materials: The following are available online at https:/ /www.mdpi.com/article/ $10.3390 /$ ijms222111567/s1.

Author Contributions: Conceptualization, M.C.; Formal analysis, T.D.M.; Funding acquisition, M.C.; Investigation, T.D.M., A.C. and E.J.M.; Methodology, F.Z. and M.C.; Supervision, M.C.; Writingoriginal draft, T.D.M. and M.C.; Writing—review \& editing, T.D.M., E.J.M., F.Z. and M.C. All authors have read and agreed to the published version of the manuscript.

Funding: This research was funded by AIRC, grant number 22894 (M.C.).

Data Availability Statement: All data in this study can be requested from the corresponding authors (tainah.marforio2@unibo.it, T.D.M.; matteo.calvaresi3@unibo.it, M.C.).

Conflicts of Interest: The authors declare no conflict of interest.

\section{References}

1. Goodarzi, S.; Da Ros, T.; Conde, J.; Sefat, F.; Mozafari, M. Fullerene: Biomedical engineers get to revisit an old friend. Mater. Today 2017, 20, 460-480. [CrossRef]

2. Castro, E.; Garcia, A.H.; Zavala, G.; Echegoyen, L. Fullerenes in biology and medicine. J. Mater. Chem. B 2017, 5, 6523-6535. [CrossRef] [PubMed]

3. Dellinger, A.; Zhou, Z.; Connor, J.; Madhankumar, A.; Pamujula, S.; Sayes, C.M.; Kepley, C.L. Application of fullerenes in nanomedicine: An update. Nanomedicine 2013, 8, 1191-1208. [CrossRef]

4. Mchedlov-Petrossyan, N.O. Fullerenes in Liquid Media: An Unsettling Intrusion into the Solution Chemistry. Chem. Rev. 2013, 113, 5149-5193. [CrossRef]

5. Nakamura, E.; Isobe, H. Functionalized Fullerenes in Water. The First 10 Years of Their Chemistry, Biology, and Nanoscience. Acc. Chem. Res. 2003, 36, 807-815. [CrossRef]

6. Bosi, S.; Da Ros, T.; Spalluto, G.; Prato, M. Fullerene derivatives: An attractive tool for biological applications. Eur. J. Med. Chem. 2003, 38, 913-923. [CrossRef]

7. Dugan, L.L.; Turetsky, D.M.; Du, C.; Lobner, D.; Wheeler, M.; Almli, C.R.; Shen, C.K.F.; Luh, T.Y.; Choi, D.W.; Lin, T.S. Carboxyfullerenes as neuroprotective agents. Proc. Natl. Acad. Sci. USA 1997, 94, 9434-9439. [CrossRef]

8. Lin, A.M.Y.; Chyi, B.Y.; Wang, S.D.; Yu, H.H.; Kanakamma, P.P.; Luh, T.Y.; Chou, C.K.; Ho, L.T. Carboxyfullerene prevents iron-induced oxidative stress in rat brain. J. Neurochem. 1999, 72, 1634-1640. [CrossRef] [PubMed]

9. Straface, E.; Natalini, B.; Monti, D.; Franceschi, C.; Schettini, G.; Bisaglia, M.; Fumelli, C.; Pincelli, C.; Pellicciari, R.; Malorni, W. C3-Fullero-tris-methanodicarboxylic acid protects epithelial cells from radiation-induced anoikia by influencing cell adhesion ability. FEBS Lett. 1999, 454, 335-340.

10. Bozdaganyan, M.E.; Orekhov, P.S.; Shaytan, A.K.; Shaitan, K.V. Comparative computational study of interaction of C60-fullerene and tris-malonyl-C60-fullerene isomers with lipid bilayer: Relation to their antioxidant effect. PLoS ONE 2014, 9, e102487. [CrossRef] 
11. Yang, X.; Ebrahimi, A.; Li, J.; Cui, Q. Fullerene-biomolecule conjugates and their biomedicinal applications. Int. J. Nanomed. 2013, 9, 77-92.

12. Bianco, A.; Da, T.; Prato, M.; Toniolo, C.; Ros, T. Da Fullerene-based Amino Acids and Peptides. J. Pept. Sci. 2001, 7, 208-219. [CrossRef]

13. Barron, A.R. [60] Fullerene-peptides: Bio-nano conjugates with structural and chemical diversity. J. Enzyme Inhib. Med. Chem. 2016, 31, 164-176. [CrossRef] [PubMed]

14. Jennepalli, S.; Pyne, S.G.; Keller, P.A. [60] Fullerenyl amino acids and peptides: A review of their synthesis and applications. RSC Adv. 2014, 4, 46383-46398. [CrossRef]

15. Pochkaeva, E.I.; Podolsky, N.E.; Zakusilo, D.N.; Petrov, A.V.; Charykov, N.A.; Vlasov, T.D.; Penkova, A.V.; Vasina, L.V.; Murin, I.V.; Sharoyko, V.V.; et al. Fullerene derivatives with amino acids, peptides and proteins: From synthesis to biomedical application. Prog. Solid State Chem. 2020, 57, 100255. [CrossRef]

16. Kurz, A.; Halliwell, C.M.; Davis, J.J.; Allen, H.; Hill, O.; Canters, G.W. A fullerene-modified protein. Chem. Commun. 1998, 433-434. [CrossRef]

17. Chen, B.X.; Wilson, S.R.; Das, M.; Coughlin, D.J.; Erlanger, B.F. Antigenicity of fullerenes: Antibodies specific for fullerenes and their characteristics. Proc. Natl. Acad. Sci. USA 1998, 95, 10809-10813. [CrossRef]

18. Guldi, D.M.; Prato, M. Excited-state properties of C60 fullerene derivatives. Acc. Chem. Res. 2000, 33, 695-703. [CrossRef] [PubMed]

19. Dallavalle, M.; Leonzio, M.; Calvaresi, M.; Zerbetto, F. Explaining Fullerene Dispersion by using Micellar Solutions. ChemPhysChem 2014, 15, 2998-3005. [CrossRef]

20. Di Giosia, M.; Nicolini, F.; Ferrazzano, L.; Soldà, A.; Valle, F.; Cantelli, A.; Marforio, T.D.; Bottoni, A.; Zerbetto, F.; Montalti, M.; et al. Stable and Biocompatible Monodispersion of C 60 in Water by Peptides. Bioconjug. Chem. 2019, 30, 808-814. [CrossRef]

21. Di Giosia, M.; Zerbetto, F.; Calvaresi, M. Incorporation of Molecular Nanoparticles Inside Proteins: The Trojan Horse Approach in Theranostics. Acc. Mater. Res. 2021, 2, 594-605. [CrossRef]

22. Belgorodsky, B.; Fadeev, L.; Kolsenik, J.; Gozin, M. Formation of a soluble stable complex between pristine C60-fullerene and a native blood protein. ChemBioChem 2006, 7, 1783-1789. [CrossRef]

23. Di Giosia, M.; Soldà, A.; Seeger, M.; Cantelli, A.; Arnesano, F.; Nardella, M.I.; Mangini, V.; Valle, F.; Montalti, M.; Zerbetto, F.; et al. A Bio-Conjugated Fullerene as a Subcellular-Targeted and Multifaceted Phototheranostic Agent. Adv. Funct. Mater. 2021, 31, 1-8. [CrossRef]

24. Calvaresi, M.; Arnesano, F.; Bonacchi, S.; Bottoni, A.; Calò, V.; Conte, S.; Falini, G.; Fermani, S.; Losacco, M.; Montalti, M.; et al. C60@Lysozyme: Direct observation by nuclear magnetic resonance of a 1:1 fullerene protein adduct. ACS Nano 2014, 8, 1871-1877. [CrossRef] [PubMed]

25. Soldà, A.; Cantelli, A.; Di Giosia, M.; Montalti, M.; Zerbetto, F.; Rapino, S.; Calvaresi, M. C60@lysozyme: A new photosensitizing agent for photodynamic therapy. J. Mater. Chem. B 2017, 5, 6608-6615. [CrossRef] [PubMed]

26. Di Giosia, M.; Bomans, P.H.H.; Bottoni, A.; Cantelli, A.; Falini, G.; Franchi, P.; Guarracino, G.; Friedrich, H.; Lucarini, M.; Paolucci, F.; et al. Proteins as supramolecular hosts for C60: A true solution of C60 in water. Nanoscale 2018, 10, 9908-9916. [CrossRef] [PubMed]

27. di Giosia, M.; Valle, F.; Cantelli, A.; Bottoni, A.; Zerbetto, F.; Calvaresi, M. C60 bioconjugation with proteins: Towards a palette of carriers for all pH ranges. Materials (Basel) 2018, 11, 691. [CrossRef]

28. Vance, S.J.; Desai, V.; Smith, B.O.; Kennedy, M.W.; Cooper, A. Aqueous solubilization of C60 fullerene by natural protein surfactants, latherin and ranaspumin-2. Biophys. Chem. 2016, 214-215, 27-32. [CrossRef]

29. Di Costanzo, L.; Geremia, S. Atomic details of carbon-based nanomolecules interacting with proteins. Molecules 2020, $25,3555$. [CrossRef]

30. Calvaresi, M.; Zerbetto, F. Baiting proteins with C60. ACS Nano 2010, 4, 2283-2299. [CrossRef]

31. Calvaresi, M.; Zerbetto, F. Fullerene sorting proteins. Nanoscale 2011, 3, 2873-2881. [CrossRef]

32. Ahmed, L.; Rasulev, B.; Kar, S.; Krupa, P.; Mozolewska, M.A.; Leszczynski, J. Inhibitors or toxins? Large library target-specific screening of fullerene-based nanoparticles for drug design purpose. Nanoscale 2017, 9, 10263-10276. [CrossRef]

33. Kim, K.-H.; Ko, D.-K.; Kim, Y.-T.; Kim, N.H.; Paul, J.; Zhang, S.-Q.; Murray, C.B.; Acharya, R.; DeGrado, W.F.; Kim, Y.H.; et al. Protein-directed self-assembly of a fullerene crystal. Nat. Commun. 2016, 7, 11429. [CrossRef]

34. Liutkus, M.; López-Andarias, A.; Mejías, S.H.; López-Andarias, J.; Gil-Carton, D.; Feixas, F.; Osuna, S.; Matsuda, W.; Sakurai, T.; Seki, S.; et al. Protein-directed crystalline 2D fullerene assemblies. Nanoscale 2020, 12, 3614-3622. [CrossRef]

35. Calvaresi, M.; Bottoni, A.; Zerbetto, F. Thermodynamics of Binding between Proteins and Carbon Nanoparticles: The Case of C60@Lysozyme. J. Phys. Chem. C 2015, 119, 28077-28082. [CrossRef]

36. Trozzi, F.; Marforio, T.D.; Bottoni, A.; Zerbetto, F.; Calvaresi, M. Engineering the Fullerene-protein Interface by Computational Design: The Sum is More than its Parts. Isr. J. Chem. 2017, 57, 547-552. [CrossRef]

37. Maoyong, S.; Guibin, J.; Junfa, Y.; Hailin, W. Inhibition of polymerase activity by pristine fullerene nanoparticles can be mitigated by abundant proteins. Chem. Commun. 2010, 46, 1404-1406. [CrossRef]

38. Fjodorova, N.; Novič, M.; Venko, K.; Rasulev, B. A comprehensive cheminformatics analysis of structural features affecting the binding activity of fullerene derivatives. Nanomaterials 2020, 10, 90. [CrossRef] 
39. Roy, P.; Bag, S.; Chakraborty, D.; Dasgupta, S. Exploring the Inhibitory and Antioxidant Effects of Fullerene and Fullerenol on Ribonuclease, A. ACS Omega 2018, 3, 12270-12283. [CrossRef]

40. Serda, M.; Szewczyk, G.; Krzysztyńska-Kuleta, O.; Korzuch, J.; Dulski, M.; Musioł, R.; Sarna, T. Developing [60] Fullerene Nanomaterials for Better Photodynamic Treatment of Non-Melanoma Skin Cancers. ACS Biomater. Sci. Eng. 2020, 6, 5930-5940. [CrossRef] [PubMed]

41. De Leon, A.; Jalbout, A.F.; Basiuk, V.A. Fullerene-amino acid interactions. A theoretical study. Chem. Phys. Lett. 2008, 452, 306-314. [CrossRef]

42. Basiuk, V.A.; González-Luciano, E. Noncovalent interactions of amino acids with fullerene C60: A dispersion-corrected DFT study. Fullerenes Nanotub. Carbon Nanostructures 2016, 24, 371-379. [CrossRef]

43. Ganazzoli, F.; Raffaini, G. Classical atomistic simulations of protein adsorption on carbon nanomaterials. Curr. Opin. Colloid Interface Sci. 2019, 41, 11-26. [CrossRef]

44. Genheden, S.; Ryde, U. The MM/PBSA and MM/GBSA methods to estimate ligand-binding affinities. Expert Opin. Drug Discov. 2015, 10, 449-461. [CrossRef] [PubMed]

45. Calvaresi, M.; Furini, S.; Domene, C.; Bottoni, A.; Zerbetto, F. Blocking the passage: C60 geometrically clogs $\mathrm{K}^{+}$channels. ACS Nano 2015, 9, 4827-4834. [CrossRef]

46. Liu, Z.; Zou, Y.; Zhang, Q.; Chen, P.; Liu, Y.; Qian, Z. Distinct binding dynamics, sites and interactions of fullerene and fullerenols with amyloid- $\beta$ peptides revealed by molecular dynamics simulations. Int. J. Mol. Sci. 2019, 20, 2048. [CrossRef]

47. Braden, B.C.; Goldbaum, F.A.; Chen, B.X.; Kirschner, A.N.; Wilson, S.R.; Erlanger, B.F. X-ray crystal structure of an antiBuckminsterfullerene antibody Fab fragment: Biomolecular recognition of C60. Proc. Natl. Acad. Sci. USA 2000, 97, 12193-12197. [CrossRef]

48. Osipov, E.M.; Hendrickson, O.D.; Tikhonova, T.V.; Zherdev, A.V.; Solopova, O.N.; Sveshnikov, P.G.; Dzantiev, B.B.; Popov, V.O. Structure of the anti-C60 fullerene antibody fab fragment: Structural determinants of fullerene binding. Acta Nat. 2019, 11, 58-65. [CrossRef]

49. Bai, C.; Lao, Z.; Chen, Y.; Tang, Y.; Wei, G. Pristine and Hydroxylated Fullerenes Prevent the Aggregation of Human Islet Amyloid Polypeptide and Display Different Inhibitory Mechanisms. Front. Chem. 2020, 8, 1-11. [CrossRef]

50. Zuo, G.; Kang, S.G.; Xiu, P.; Zhao, Y.; Zhou, R. Interactions between proteins and carbon-based nanoparticles: Exploring the origin of nanotoxicity at the molecular level. Small 2013, 9, 1546-1556. [CrossRef]

51. Bai, Y.; Wu, X.; Ouyang, P.; Shi, M.; Li, Q.; Maimaiti, T.; Lan, S.; Yang, S.T.; Chang, X.L. Surface modification mediates the interaction between fullerene and lysozyme: Protein structure and antibacterial activity. Environ. Sci. Nano 2021, 8, 76-85. [CrossRef]

52. Wu, X.; Yang, S.T.; Wang, H.; Wang, L.; Hu, W.; Cao, A.; Liu, Y. Influences of the size and hydroxyl number of fullerenes / fullerenols on their interactions with proteins. J. Nanosci. Nanotechnol. 2010, 10, 6298-6304. [CrossRef]

53. Yang, S.T.; Wang, H.; Guo, L.; Gao, Y.; Liu, Y.; Cao, A. Interaction of fullerenol with lysozyme investigated by experimental and computational approaches. Nanotechnology 2008, 19, 395101. [CrossRef]

54. Giełdoń, A.; Witt, M.M.; Gajewicz, A.; Puzyn, T. Rapid insight into C60 influence on biological functions of proteins. Struct. Chem. 2017, 28, 1775-1788. [CrossRef]

55. Hirano, A.; Kameda, T. Aromaphilicity Index of Amino Acids: Molecular Dynamics Simulations of the Protein Binding Affinity for Carbon Nanomaterials. ACS Appl. Nano Mater. 2021, 4, 2486-2495. [CrossRef]

56. Dasetty, S.; Barrows, J.K.; Sarupria, S. Adsorption of amino acids on graphene: Assessment of current force fields. Soft Matter 2019, 15, 2359-2372. [CrossRef] [PubMed]

57. Hirano, A.; Tanaka, T.; Kataura, H.; Kameda, T. Arginine side chains as a dispersant for individual single-wall carbon nanotubes. Chem. A Eur. J. 2014, 20, 4922-4930. [CrossRef] [PubMed]

58. Iwashita, K.; Shiraki, K.; Ishii, R.; Tanaka, T.; Hirano, A. Arginine suppresses the adsorption of lysozyme onto single-wall carbon nanotubes. Chem. Lett. 2016, 45, 952-954. [CrossRef]

59. Calvaresi, M.; Hoefinger, S.; Zerbetto, F. Probing the structure of lysozyme-carbon-nanotube hybrids with molecular dynamics. Chem. A Eur. J. 2012, 18, 4308-4813. [CrossRef] [PubMed]

60. Wu, E.; Coppens, M.-O.; Garde, S. Role of Arginine in Mediating Protein-Carbon Nanotube Interactions. Langmuir 2015, 31, 1683-1692. [CrossRef] [PubMed]

61. Li, J.; Garg, M.; Shah, D.; Rajagopalan, R. Solubilization of aromatic and hydrophobic moieties by arginine in aqueous solutions. J. Chem. Phys. 2010, 133, 054902. [CrossRef]

62. Di Giosia, M.; Valle, F.; Cantelli, A.; Bottoni, A.; Zerbetto, F.; Fasoli, E.; Calvaresi, M. High-throughput virtual screening to rationally design protein-Carbon nanotube interactions. Identification and preparation of stable water dispersions of protein-Carbon nanotube hybrids and efficient design of new functional materials. Carbon 2019, 147, 70-82. [CrossRef]

63. Di Giosia, M.; Marforio, T.D.; Cantelli, A.; Valle, F.; Zerbetto, F.; Su, Q.; Wang, H.; Calvaresi, M. Inhibition of $\alpha$-chymotrypsin by pristine single-wall carbon nanotubes: Clogging up the active site. J. Colloid Interface Sci. 2020, 571, 174-184. [CrossRef]

64. Maier, J.A.; Martinez, C.; Kasavajhala, K.; Wickstrom, L.; Hauser, K.E.; Simmerling, C. ff14SB: Improving the Accuracy of Protein Side Chain and Backbone Parameters from ff99SB. J. Chem. Theory Comput. 2015, 11, 3696-3713. [CrossRef]

65. Case, D.A.; Betz, R.M.; Cerutti, D.S.; Cheatham, T.E., III; Darden, T.A.; Duke, R.E.; Giese, T.J.; Gohlke, H.; Goetz, A.W.; Homeyer, N.; et al. AMBER16; University of California: San Francisco, CA, USA, 2016. 
66. Miller, B.R.; McGee, T.D.; Swails, J.M.; Homeyer, N.; Gohlke, H.; Roitberg, A.E. MMPBSA.py: An efficient program for end-state free energy calculations. J. Chem. Theory Comput. 2012, 8, 3314-3321. [CrossRef]

67. Roe, D.R.; Cheatham, T.E., III. PTRAJ and CPPTRAJ: Software for Processing and Analysis of Molecular Dynamics Trajectory Data. J. Chem. Theory Comput. 2013, 9, 3084-3095. [CrossRef]

68. Zhang, L.; Lemonnier, J.-F.; Acocella, A.; Calvaresi, M.; Zerbetto, F.; Leigh, D.A. Effects of knot tightness at the molecular level. Proc. Natl. Acad. Sci. USA 2019, 116, 2452-2457. [CrossRef]

69. Di Silvio, S.; Bologna, F.; Milli, L.; Giuri, D.; Zanna, N.; Castellucci, N.; Monari, M.; Calvaresi, M.; Górecki, M.; Angelici, G.; et al Elusive $\pi$-helical peptide foldamers spotted by chiroptical studies. Org. Biomol. Chem. 2020, 18, 865-877. [CrossRef] [PubMed] 